\title{
Screening of Barley Breeding Lines for Resistance to Common Root Rot Disease through Incidence and Severity Parameters
}

\author{
M. I. E. ARABI*, E. AL-SHEHADAH and M. JAWHAR \\ Department of Molecular Biology and Biotechnology, AECS, P. O. Box 6091 Damascus, Syria
}

(Received: 27 March 2019; accepted: 4 April 2019)

\begin{abstract}
Cochliobolus sativus, the causal agent of common root rot (CRR), is a devastating fungal pathogen of barley that can cause significant yield losses worldwide. The development of resistant cultivars has proven difficult, therefore, in this work, CRR-resistant barley germplasm was developed by crossing three resistant-by-susceptible cultivars currently used in Europe and West Asia. Following greenhouse evaluations of 150 doubled haploid lines derived from these crosses, 40 lines were evaluated under artificial infection conditions using incidence and severity parameters during two consecutive seasons. Data showed significant differences among barley lines with a continuum of resistance levels ranging from highly susceptible to resistant which were consistent in both seasons. However, five promising lines had slightly lower CRR disease than the others. Additionally, significant differences $(P<0.05)$ in mean incidence and severity values were found among lines, with values being consistently higher in the susceptible ones. However, CRR severity increased linearly as incidence increased in both seasons. All together, the present study suggests that, the newly identified resistance lines can serve as potential donors for ongoing CRR resistance breeding program to generate high-yielding commercial barley cultivars, and that the positive correlation between CRR parameters I and S may be beneficial for many types of studies on this disease.
\end{abstract}

Keywords: Barley (Hordeum vulgare L.), common root rot, resistance, incidence, severity.

Barley (Hordeum vulgare L.), is one of the oldest cultivated crops grown worldwide. It has a special significance in dryland agriculture due to its ability to withstand severe drought in addition to low input requirements for its successful cultivation (Fernandez et al., 2009; Al-Sadi, 2017). In Syria, barely is almost exclusively seeded under rainfed conditions, and changing farming systems, in particular, the replacement of traditional barley rotations as well as the replacement of traditional cultivars may have a large influence on plant diseases (Van Leur, 1991).

Common root rot caused by Cochliobolus sativus (Ito and Kurib.) Drechsler ex Dastur (anamorph Bipolaris sorokiniana (Sacc.) Shoemaker), is consistently one of the most damaging diseases of wheat and barley worldwide (Murray and Brennan, 2010; Fernandez et al., 2014). CRR is considered economically important because it can cause marked reduction in yield and quality of the crop (Van Leur et al., 1997; Kumar et al., 2002). This disease produces a brown to black discoloration of the subcrown internode 
(SCI), therefore, the presence and severity can be determined by pulling up plants and examining SCI for disease (Stack and McMullen, 1999; Mathre et al., 2003).

The economic damage caused by CRR can be avoided by using large amounts of fungicides or by planting resistant genotypes, with the latter option being the more economically and environmentally appropriate solution (Bailey et al., 1997), especially in developing countries where most farmers are small to marginal and unable to afford costly fungicides and other technologies. However, in Syria, sources of complete resistance to CRR have not been identified, and current barley cultivars are considered to be only moderately resistant toward this disease (Van Leur et al., 1997; Arabi and Jawhar 2002).

Since CRR is highly influenced by environment and the resistance is quantitative and achieving higher level of resistance in barely cultivars is difficult (Lehmensiek et al., 2010; Xu et al., 2018), therefore, screening of a larger number of genotypes is needed to identify new resistant sources. On the other hand, CRR assessment often based on two parameters incidence and severity, however, incidence is a measure of only one of two possible states, diseased or not diseased. Thus incidence is quicker, easier, precise, and reproducible to measure than severity. However, severity is often considered a more important and useful measure of disease intensity than incidence for determining the effectiveness of disease management strategies (Campbell and Madden, 1990). Consequently, a quantitative relationship between incidence and severity would greatly facilitate the evaluation of disease intensity when accurate assessments of severity are not available or possible (Seem, 1984).

The purpose of the present study was to screen barley breeding lines for resistance to CRR disease through incidence and severity parameters. Barley cultivars presently grown in Europe and West Asia were used in this study to identify new sources of resistance in adapted genetic backgrounds and in plant types agronomically acceptable to farmers.

\section{Materials and Methods}

\section{Plant material}

A total of 40 out of 150 barley double haploid lines produced according to Kasha and Kao (1970) were screened on the basis of agronomic characteristics and evaluated in this study (Table 1). These lines were produced through three resistant-by-susceptible barley crosses made between four parents possessing different CRR reactions. Arabi Abiad is a Syrian local cultivar, Arrivate was received from USA, PK36-130 is a Pakistan cultivar and IC-9 is a new cultivar developed at ICARDA (International Center for Agricultural Research in the Dry Areas).

\section{Inoculum preparation}

The $C$. sativus CRR16 was the most virulent and prevalent strain in the barley-growing areas of Syria (Arabi and Jawhar, 2002), and therefore it was used for artificial screening in the present study. The fungal mycelia were transferred from a stock culture into Petri dishes containing potato dextrose agar (PDA, DIFCO, Detroit, MI, USA) 
Table 1

Parental crosses and progeny susceptibility to common root rot (CRR; Cochliobolus sativus)*

\begin{tabular}{llcc}
\hline \multirow{2}{*}{ Cross } & \multicolumn{2}{c}{ Progeny } \\
\cline { 2 - 4 } & Tolerant & Moderate & Severe \\
\hline Arabi Abiad $\times$ IC-9 & 2 & 9 & 6 \\
PK36-130 $\times$ IC-9 & 1 & 7 & 9 \\
PK36-130 $\times$ Arrivate & 5 & - & 1 \\
Total & 8 & 16 & 16 \\
\hline
\end{tabular}

*Based on a scale described by Ledingham et al. (1973).

with $13 \mathrm{mg} / \mathrm{I}$ kanamycin sulphate and incubated for 10 days at $21 \pm 1{ }^{\circ} \mathrm{C}$ in the dark. Conidia were collected by flooding the plate with $10 \mathrm{~mL}$ of sterile distilled water and scraping the colony surface with a glass slide to dislodge the conidia. The resulting conidial suspension was adjusted to $5 \times 10^{5}$ conidia $/ \mathrm{mL}$.

\section{Field trials}

The location of the experiments was chosen to be favorable for the development of CRR disease at a site approximately $55 \mathrm{~km}$ south of Damascus for two years, under natural rainfed conditions ( $250 \mathrm{~mm}$ annual rainfall). Seeds were inoculated by mixing thoroughly with peat-gum-conidia inoculums (40 $\mathrm{ml}$ of spore suspension was mixed in a plastic Petri dish with $50 \mathrm{~g}$ sterile neutralized peat) (Van Leur, 1991), and planted at a depth of $6 \mathrm{~cm}$ to promote long subcrown internodes (Kokko et al., 1995) in a randomized complete block design, with three replicate plots. Plot area was $1 \times 1 \mathrm{~m}$ with a $1-\mathrm{m}$ wide borders. Each plot consisted of five rows $25 \mathrm{~cm}$ apart with 50 seeds sown per row. Weeds were controlled by pre- and post-emergence herbicides as appropriate. Soil fertilizers were drilled before sowing at a rate of $50 \mathrm{~kg} / \mathrm{ha}$ urea $(46 \% \mathrm{~N})$ and $27 \mathrm{~kg} /$ ha superphosphate $(33 \% \mathrm{P})$.

\section{CRR assessments}

Assessments were made visually at several systematically selected sampling sites, 20-25 subsampling from each row were taken at random from each replication. Subcrown internodes (SCIs) were examined 8 weeks post inoculation by measuring the percentage of SCIs surface showing CRR symptoms using a scale described by Ledingham et al. (1973), where the plants are placed into one of three groups as follows: tolerant 1 to $25 \%$, moderate 26 to $50 \%$, and severe (greater than 50\%) of the SCIs covered by lesions.

\section{Statistical analyses}

Data was subjected to analysis of variance using the STAT-ITCF statistical programme (2nd version). Differences between means were evaluated for significance by using Newman-Keuls test at 5\% probability level (Anonymous, 1988). The assumption of coincidence for each year was tested using the ANOVA procedure implemented in the software package Statistica 6.1. Years were set as the categorical variable and coincidence 
was tested by simultaneously checking year's effect combined with its interaction with the incidence (Neter and Wasserman, 1974).

\section{Results and Discussion}

In this work, four barley parents with different resistance levels to CRR infections were used. As shown in Fig. 1. CRR caused more severe infection on the susceptible parents 'Arrivate' and 'Arabi Abiad' as compared with the resistant ones. Furthermore, the disease symptoms (discoloration and necrosis of the SCIs) were typically observed in infected plants with the severity values being consistently higher in the susceptible parents (data not shown). These results are in agreement with our previous observations under natural conditions (Arabi and Jawhar, 2002).

According to a scale described by Ledingham et al. (1973), the reactions of the 40 progeny lines to CRR under field tests were classified into 8 lines as tolerant, 16 moderate and 16 severe group (Table 1$)$. However, significant differences $(P<0.05)$ in mean severity values were detected among different lines, and a continuum of genotypic reactions to the virulent strain CRR16 from resistant to susceptible was observed (Table 2).

The data showed that five lines (B08-AS-16, -34, -35, -39 and -40) were classified as resistant in both seasons, whereas lines B08-AS-1 and -2 were the most susceptible lines (Table 2). The other lines had CRR ratings that ranged between moderately resistant and susceptible. Significant correlation coefficient $(r=0.66, P=0.001)$ was found between the two seasons for CRR reaction, indicating that lines reacted similarly to $C$. sativus populations under field conditions.

On the other hand, the proportion of diseased SCIs increased linearly as the proportion of SCI showing CRR symptoms (Fig. 2), and there was no difference in the slopes and intercepts of their relationship between the two seasons, as it was shown by the test coincidence $\left(\mathrm{F}_{3,32}=1.338, P=0.187\right)$. However, the overall response to CRR for the two seasons of this work differed with the differences in susceptibility levels of the lines, and

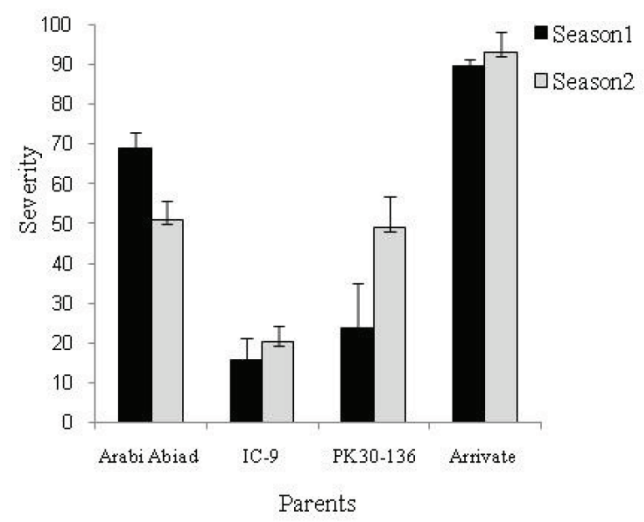

Fig. 1. Frequency of CRR reactions incited on the barley parents (Arabi Abiad, Arrivate, PK30-130 and IC-9), 7 weeks after infection during two seasons. Error bars are representative of the standard error (Mean $\pm \mathrm{SD}, n=3$ ) 
Table 2

Mean common root rot disease incidence (I) and severity (S) of the barley lines under field conditions during two seasons

\begin{tabular}{|c|c|c|c|c|c|c|}
\hline \multirow[t]{2}{*}{ Cross } & \multirow[t]{2}{*}{ No. } & \multirow[t]{2}{*}{ Lines } & \multicolumn{2}{|l|}{ Season1 } & \multicolumn{2}{|l|}{ Season2 } \\
\hline & & & $\mathrm{S}$ & I & $\mathrm{S}$ & I \\
\hline \multirow[t]{17}{*}{ Arabi Abiad $\times$ IC-9 } & 1 & B08-AS-1 & $93.87 a^{*}$ & 100 & $86 a$ & 100 \\
\hline & 2 & B08-AS-2 & $77.40 \mathrm{ab}$ & 80 & $83.87 \mathrm{ab}$ & 100 \\
\hline & 3 & B08-AS-3 & $51.33 \mathrm{cde}$ & 66 & $82.77 \mathrm{ab}$ & 100 \\
\hline & 4 & B08-AS-4 & $61.67 \mathrm{bc}$ & 80 & $80.53 \mathrm{ab}$ & 98 \\
\hline & 5 & B08-AS-5 & 40.33hij & 50 & $72.63 \mathrm{abc}$ & 90 \\
\hline & 6 & B08-AS-6 & 37hij & 50 & $72 \mathrm{bcd}$ & 91 \\
\hline & 7 & B08-AS-7 & $63 \mathrm{bc}$ & 70 & $64.4 \mathrm{cde}$ & 80 \\
\hline & 8 & B08-AS-8 & 46.1efg & 60 & $54.4 \mathrm{de}$ & 65 \\
\hline & 9 & B08-AS-9 & $17.40 \mathrm{ij}$ & 35 & $7.67 \mathrm{j}$ & 15 \\
\hline & 10 & B08-AS-10 & $30.33 \mathrm{ij}$ & 52 & $6.67 \mathrm{j}$ & 15 \\
\hline & 11 & B08-AS-11 & $90 a$ & 100 & $54.17 \mathrm{de}$ & 77 \\
\hline & 12 & B08-AS-12 & 31hij & 55 & $50.2 \mathrm{def}$ & 59 \\
\hline & 13 & B08-AS-13 & 31.33hij & 40 & $36.1 \mathrm{efg}$ & 44 \\
\hline & 14 & B08-AS-14 & 40.98ghi & 52 & 30,46 & 40 \\
\hline & 15 & B08-AS-15 & 42.33ghi & 60 & $20.53 \mathrm{hij}$ & 25 \\
\hline & 16 & B08-AS-16 & $6.8 \mathrm{j}$ & 10 & 18.53hij & 20 \\
\hline & 17 & B08-AS-17 & 27.43hij & 39 & 15.43hij & 20 \\
\hline \multirow[t]{17}{*}{ PK30-136 × IC-9 } & 18 & B08-AS-18 & $81.67 \mathrm{ab}$ & 100 & $82.73 \mathrm{ab}$ & 100 \\
\hline & 19 & B08-AS-19 & 39hij & 55 & $78.33 \mathrm{abc}$ & 90 \\
\hline & 20 & B08-AS-20 & 33.33hij & 40 & $75.87 \mathrm{abc}$ & 90 \\
\hline & 21 & B08-AS-21 & $78.23 \mathrm{ab}$ & 90 & $73.27 \mathrm{abc}$ & 88 \\
\hline & 22 & B08-AS-22 & $52.67 \mathrm{bcd}$ & 60 & $67.53 \mathrm{cde}$ & 80 \\
\hline & 23 & B08-AS-23 & $66.76 b c$ & 78 & $62.87 \mathrm{cde}$ & 81 \\
\hline & 24 & B08-AS-24 & $63.5 \mathrm{bc}$ & 80 & $62.2 \mathrm{cde}$ & 69 \\
\hline & 25 & B08-AS-25 & $52.2 \mathrm{bcd}$ & 55 & $58.3 \mathrm{de}$ & 60 \\
\hline & 26 & B08-AS-26 & $69.33 b c$ & 80 & $56.67 \mathrm{de}$ & 70 \\
\hline & 27 & B08-AS-27 & $44 f g h$ & 55 & $5 \mathrm{j}$ & 10 \\
\hline & 28 & B08-AS-28 & 40.33hij & 50 & 42.78def & 53 \\
\hline & 29 & B08-AS-29 & $69.53 b c$ & 80 & $34.7 \mathrm{fgh}$ & 50 \\
\hline & 30 & B08-AS-30 & 33.33hij & 41 & $31.53 \mathrm{ghi}$ & 50 \\
\hline & 31 & B08-AS-31 & 26.67hij & 44 & 26.63hij & 44 \\
\hline & 32 & B08-AS-32 & $63.33 b c$ & 80 & 26.63hij & 41 \\
\hline & 33 & B08-AS-33 & 41.67ghi & 50 & 25.53hij & 40 \\
\hline & 34 & B08-AS-34 & $7.83 \mathrm{j}$ & 15 & $8.63 \mathrm{ij}$ & 12 \\
\hline \multirow[t]{6}{*}{ PK30-136× Arrivate } & 35 & B08-AS-35 & 17hij & 20 & 19.33hij & 25 \\
\hline & 36 & B08-AS-36 & $66 b c$ & 80 & $53.78 \mathrm{de}$ & 66 \\
\hline & 37 & B08-AS-37 & 23.43hij & 30 & $33.3 \mathrm{fgh}$ & 40 \\
\hline & 38 & B08-AS-38 & 33.67hij & 49 & 16.97hij & 20 \\
\hline & 39 & B08-AS-39 & 23.33hij & 40 & 20.49hij & 25 \\
\hline & 40 & B08-AS-40 & $21.77 \mathrm{hij}$ & 40 & $9.7 \mathrm{ij}$ & 10 \\
\hline
\end{tabular}

* Values within a column followed by different letters are significantly different at $\mathrm{P}<0.05$ according to Newman-Keuls test. 


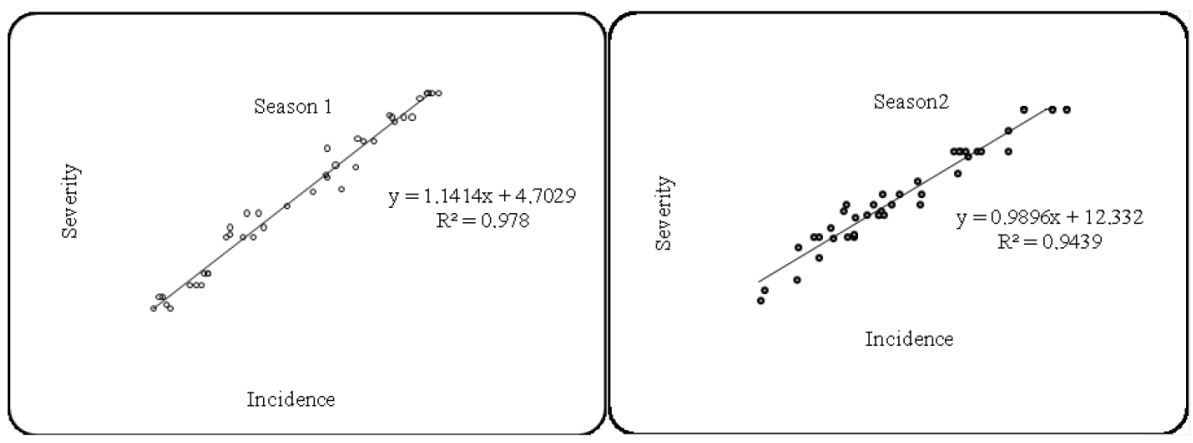

Fig. 2. Incidence (I; proportion of diseased SCIs) and severity (S; proportion of SCI showing CRR symptoms) of barley common root rot for the two seasons. Data points shown as $\left(^{\circ}\right)$ represent many hidden observations

that resistant lines to CRR might have different reaction to the spread of the fungus within the infected plants. So, incidence-severity analysis was important in evaluating disease resistance as described by McRoberts et al. (2003).

One of the major objectives of the Syrian barley breeding program is to develop high-yielding cultivars with resistance to CRR disease through the transfer of genes from resistant sources. In this work, all the five resistant lines maintained their reaction during the two growing seasons, and this stability levels may have been evidence of their resistant levels. Moreover, the population of crosses Arabi Abiad/IC-9 and PK/IC-9 will be used for mapping genes associated with CRR resistance. Some lines from this cross were recovered with a high degree of resistance to CRR. These will be tested in multilocation trials to test their stability and adaptability.

Additionally, the data demonstrated that barley lines have sufficient variability for infection response to CRR pathogen. Therefore, inclusion of this diverse germplasm in the barley breeding program might increase the dominance effect and epistatic variations controlling quantitative traits such as CRR resistance (Halward and Wynne, 1991; Lehmensiek et al., 2010). These would also lead to extend segregation for various traits and in obtaining useful recombinants/transgressive segregants in the further generations.

This study showed that the barley breeding lines had diversity for infection response to CRR pathogen. Five promising sources of resistance were identified that could be considered as possible donors in further barley breeding programs. In addition, a positive relationship between proportion of diseased SCIs and the proportion of SCI showing CRR symptoms was detected, this will be important for the researchers to identify the cultivars with unusually large or small severities for a given incidence (McRoberts et al., 2003; Paul et al., 2005). Moreover, estimation of this parameter would substantially reduce the work load in CRR quantification in field surveys and treatment comparisons.

\section{Acknowledgements}

The authors wish to thank the Director General of AECS and the Head of the Molecular Biology and Biotechnology Department for their continuous support throughout this work. 


\section{Literature}

Al-Sadi, A. M. (2017): Epidemiology and management of fungal diseases in dry environments. In: M. Farooq and K. Siddique (eds): Innovations in Dryland Agriculture. Springer International Publishing, pp. 187-209.

https://doi.org/10.1007/978-3-319-47928-6 7. Sultan Gaboos University, Oman.

Anonymous (1988): STAT-ITCF, Programme, MICROSTA, realized by ECOSOFT, $2^{\text {nd }}$ Ver. Institut Technique des Cereals et des Fourrages Paris, 55 p.

Arabi, M. I. E. and Jawhar, M. (2002): Virulence spectrum to barley in some isolates of Cochliobolus sativus from Syria. J. Plant Pathol. 84, 35-39.

Bailey, K. L., Duczek, L. J. and Potts, D. A. (1997): Inoculation of seeds with Bipolaris sorokiniana and soil fumigation methods to determine wheat and barley tolerance and yield losses caused by common root rot. Can. J. Plant Sci. 77, 691-698.

Campbell, C. L. and Madden, L. V. (1990): Introduction to Plant Disease Epidemiology. John Wiley and Sons, New York, 532 p.

Fernandez, M. R., Holzgang, G. and Turkington, T. K. (2009): Common root rot and crown rot of barley crops across Saskatchewan and in north-central Alberta. Can. J. Plant Pathol. 31, 96-102.

Fernandez, M. R., Fox, S. L., Hucl, P., Singh, A. K. and Stevenson, F. C. (2014): Root rot severity and fungal populations in spring common, durum and spelt wheat, and Kamut grown under organic management in Western Canada. Can. J. Plant Sci. 94, 937-946.

Halward, T. M. and Wynne, J. C. (1991): Generation means analysis for productivity in two diverse peanut crosses. Theor. Appl. Genet. 82, 784-792.

Kokko, E. G., Conner, R. L., Kozub, G. C. and Lee, B. (1995): Effects of common root rot on discoloration and growth of spring wheat root system. Phytopathology 85, 203-208.

Kasha, K. J. and Kao, K. N. (1970): High frequency haploid production in barley (Hordeum vulgare L.). Nature 225, 874-876.

Kumar, J., Schafer, P., Huckelhoven, R., Langen, G., Baltruschat, H., Stein, E., Nagarajan, S. and Kogel, H. K. (2002): Bipolaris sorokiniana, a cereal pathogen of global concern: cytological and molecular approaches towards better control. Mol. Plant Pathol. 3, 185-195.

Ledingham, R. J., Atkinson, T. G, Horricks, J. S., Mills, J. T., Piening, L. J. and Tinline, R. D. (1973). Wheat losses due to common root rot in the prairie provinces of Canada, 1969-1971. Can. Pl. Dis. Surv. 53, $113-122$.

Lehmensiek, A., Bovill, J., Sutherland, M. W. and McNamara, R. B. (2010): Genomic regions associated with common root rot resistance in the barley variety Delta. Aust. Plant Pathol. 39, 241-246.

Mathre, D. E., Johnston, R. H. and Grey, W. E. (2003): Diagnosis of common root rot of wheat and barley. Online. Plant Health Progress.

McRoberts, N., Hughes, G. and Madden, L. V. (2003): The theoretical basis and practical application of relationships between different disease intensity measures in plants. Ann. Appl. Biol. 142, 191-211.

Murray, G. M. and Brennan, J. P. (2010): Estimating disease losses to the Australian barley industry. Aust. Plant Pathol. 39, 85 .

Neter, J. and Wasserman, W. (1974): Applied Linear Statistical Models. Richard D. Irwin and Co., Homewood, IL. 842 p.

Paul, P. A., El-Allaf, S. M., Lipps, P. E. and Madden, L. V. (2005): Relationships between incidence and severity of Fusarium head blight on winter wheat in Ohio. Phytopathology 95, 1049-1060.

Seem, R. C. (1984): Disease incidence and severity relationships. Ann. Rev. Phytopath. 22, 133-150.

Stack, R. W. and McMullen, M. (1999): Root and crown rots of small grains. North Dakota State University Extension Publication 785 p.

Xu, F., Yang, G., Wang, J., Yuli Song, Y., Liu, L., Zhao, K., Li, Y. and Han, Z. (2018): Spatial distribution of root and crown rot fungi associated with winter wheat in the north China plain and its relationship with climate variables. Front Microbiol. 9, 1054.

Van Leur, J. G. (1991): Testing barley for resistance to Cochliobolus sativus at ICARDA, Syria. In: R. D. Tinline (ed.): Proc. of $1^{\text {st }}$ International Workshop on Common Root Rot of Cereals, Saskatoon, pp. 128-134.

Van Leur, J. G., Alamdar, M. Z. and Khawatmi, S. (1997): Effect of Cochliobolus sativus on yields of barley under experimental conditions in northern Syria. Aust. J. Agric. Res. 48, 1-7. 
